\title{
CROSS-CULTURAL DIFFERENCES IN DRIVER RISK-TAKING
}

\author{
Michael SivaK \\ The University of Michigan, Transportation Research Institute, \\ Ann Arbor, MI 48109-2150, U.S.A. \\ JOSÉ SOLER \\ The University of Valencia, Faculty of Psychology, Valencia, Spain
}

ULRICH TRÄNKLE

The University of Münster, Institute of Psychology, Münster, Federal Republic of Germany

(Received 13 May 1988)

\begin{abstract}
This study investigated differences in simulated driver risk-taking behavior among U.S., Spanish, and West German subjects. The task consisted of performing a simulated intersection crossing on a video display. Subjects were shown an intersection with moving traffic on a horizontal road, and they were asked to attempt (under time pressure) a fixed number of crossings with a car moving vertically. The subjects in all three countries included younger, middle-aged, and older persons of both sexes. The following are the main findings: (1) The performance of West German subjects tended to differ from those of U.S. and Spanish subjects. Specifically, West German subjects attempted fewer crossings, had a higher probability of success, and had greater safety margins. (2) Target risk-level of performance, measured by probability of successful crossings, was not affected by age or sex. (3) Probability of attempted crossings was greater for males and younger subjects than for females and older subjects. (4) Similarly, safety margins during attempted crossings were smaller for males and younger subjects than for females and older subjects. These results suggest that there are differences among countries in the target risk-level of performance. However, the present findings imply that within each country all subjects (regardless of age and sex) tended to have the same target risk-level. To attain this risk-level of performance, males and younger subjects (because of their presumed superior psychomotor skills and/or greater experience with video tasks) attempted to cross more gaps (and, consequently, smaller gaps), with resulting smaller safety margins.
\end{abstract}

\section{INTRODUCTION}

This study is one of three studies performed as part of research on cross-cultural differences in driver risk-behavior. The other two studies investigated perception of risk in slide-projected photographs of traffic scenes (Sivak, Soler, Tränkle, and Spagnhol 1989), and driver self-assessment (Sivak, Soler, and Tränkle 1989).

The present study focused on driver risk-taking in a simulated intersection crossing in the United States, Spain, and West Germany. The primary objective was to investigate cross-cultural differences. The secondary objective was to study age- and sex-related differences.

Driver risk-taking, as a relevant factor in traffic safety, has been the topic of many studies and theoretical controversies (for recent reviews and theories see Evans 1986; Fuller 1984; McKenna 1988; Summala 1988; van der Molen and Bötticher 1988; Wilde 1988). However, the present study is, apparently, the first published experimental investigation of cross-cultural differences in simulated driver risk-taking.

\section{METHOD}

Task

The task in this study was to perform simulated intersection crossings on a video display (see Fig. 1). Subjects were shown an intersection with moving traffic on the horizontal (main) road. This traffic contained a variety of gap sizes. A stationary car was positioned at a stop sign on the vertical (secondary) road. By pressing the space bar on the computer keyboard, the stationary car began to move upwards, crossing the 


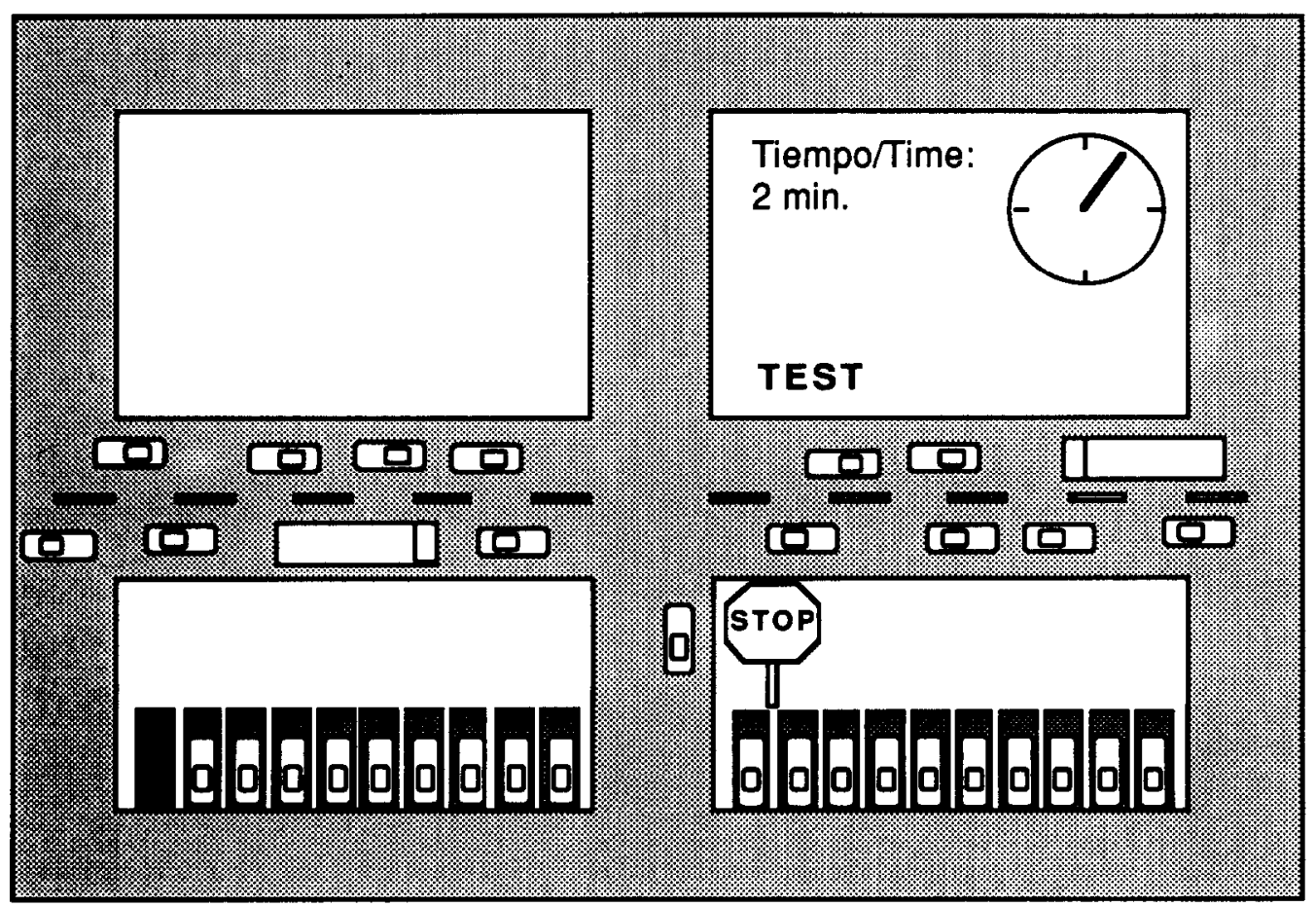

Fig. 1. Schematic of the experimental display.

horizontal road. If the car successfully crossed the road (i.e. without hitting any of the moving cars on the horizontal road), another stationary car appeared at the stop sign. On the other hand, if the car hit another vehicle while attempting to cross the road, the scene "froze" for five seconds with a loud beep. After this delay another car appeared at the stop sign.

The vehicles on the horizontal road moved at a constant speed of approximately 24 $\mathrm{mm} / \mathrm{sec}$. After subjects pressed the space bar on the computer keyboard, the subjects' cars accelerated in such a fashion that it took them about $1 \mathrm{sec}$ to clear the intersection.

\section{Equipment}

IBM-PC/XT (or compatible) microcomputers were used in all three countries. To assure the same speed of the moving elements in the display, the clock speeds and the microprocessors were the same in all countries (i.e. $4.77 \mathrm{MHz}$ and 8088 , respectively). Similarly, to assure compatibility in the color graphics of the display, only color monitors with CGA graphics were used.

\section{Subjects}

Sixty subjects were tested in each country, for a total of 180 subjects. In each country there were 20 subjects ( 10 males and 10 females) in each of the following three age groups: 19-21 year olds, 35-45 year olds, and 65-75 year olds. (One West German subject was 18 years of age.) The distributions of the ages of subjects in each group are shown in Table 1. The U.S. subjects, who were paid for their participation, came primarily from Ann Arbor, Michigan, a city with a population of approximately 120,000. The Spanish subjects, who were tested without reimbursement, came primarily from Valencia, a city with a population of approximately 800,000 . The West German subjects came primarily from Münster, a city with a population of approximately 270,000 , and were paid for their participation. 
Table 1. Age distributions of subjects

\begin{tabular}{|c|c|c|c|c|c|c|}
\hline Group & Country & Sex & $\mathbb{N}$ & $\begin{array}{l}\text { Min } \\
\text { Age }\end{array}$ & $\begin{array}{l}\text { Max } \\
\text { Age }\end{array}$ & $\begin{array}{r}\text { Mean } \\
\text { Age }\end{array}$ \\
\hline \multirow[t]{3}{*}{ Younger } & U.S.A. & $\begin{array}{l}\text { Males } \\
\text { Pemales }\end{array}$ & $\begin{array}{l}10 \\
10\end{array}$ & $\begin{array}{l}19 \\
19\end{array}$ & $\begin{array}{l}21 \\
21\end{array}$ & $\begin{array}{l}20.5 \\
20.3\end{array}$ \\
\hline & Spain & $\begin{array}{l}\text { Males } \\
\text { Females }\end{array}$ & $\begin{array}{l}10 \\
10\end{array}$ & $\begin{array}{l}19 \\
19\end{array}$ & $\begin{array}{l}21 \\
21\end{array}$ & $\begin{array}{l}19.9 \\
20.5\end{array}$ \\
\hline & West Germany & $\begin{array}{l}\text { males } \\
\text { Females }\end{array}$ & $\begin{array}{l}10 \\
10\end{array}$ & $\begin{array}{l}19 \\
18\end{array}$ & $\begin{array}{l}21 \\
21\end{array}$ & $\begin{array}{l}20.0 \\
20.6\end{array}$ \\
\hline \multirow[t]{3}{*}{ Middle-Aged } & U.S.A. & $\begin{array}{l}\text { Males } \\
\text { Females }\end{array}$ & $\begin{array}{l}10 \\
10\end{array}$ & $\begin{array}{l}36 \\
35\end{array}$ & $\begin{array}{l}45 \\
45\end{array}$ & $\begin{array}{l}40.6 \\
40.0\end{array}$ \\
\hline & Spain & $\begin{array}{l}\text { Males } \\
\text { Females }\end{array}$ & $\begin{array}{l}10 \\
10\end{array}$ & $\begin{array}{l}38 \\
35\end{array}$ & $\begin{array}{l}45 \\
45\end{array}$ & $\begin{array}{l}41.5 \\
41.0\end{array}$ \\
\hline & West Germany & $\begin{array}{l}\text { Males } \\
\text { Females }\end{array}$ & $\begin{array}{l}10 \\
10\end{array}$ & $\begin{array}{l}35 \\
35\end{array}$ & $\begin{array}{l}43 \\
44\end{array}$ & $\begin{array}{l}38.6 \\
37.5\end{array}$ \\
\hline \multirow[t]{3}{*}{ older } & U.S.A. & $\begin{array}{l}\text { Males } \\
\text { Females }\end{array}$ & $\begin{array}{l}10 \\
10\end{array}$ & $\begin{array}{l}66 \\
65\end{array}$ & $\begin{array}{l}74 \\
74\end{array}$ & $\begin{array}{l}70.2 \\
70.2\end{array}$ \\
\hline & Spain & $\begin{array}{l}\text { Males } \\
\text { Females }\end{array}$ & $\begin{array}{l}10 \\
10\end{array}$ & $\begin{array}{l}65 \\
65\end{array}$ & $\begin{array}{l}75 \\
74\end{array}$ & $\begin{array}{l}71.9 \\
66.7\end{array}$ \\
\hline & West Germany & $\begin{array}{l}\text { Males } \\
\text { Females }\end{array}$ & $\begin{array}{l}10 \\
10\end{array}$ & $\begin{array}{l}64 \\
65\end{array}$ & $\begin{array}{l}75 \\
75\end{array}$ & $\begin{array}{l}68.4 \\
68.3\end{array}$ \\
\hline
\end{tabular}

\section{Procedure}

At the beginning of the session, subjects were given 12 practice trials. For the actual testing, subjects were presented with 20 cars on the bottom of the display (see Fig. 1). Subjects were instructed to attempt to cross the intersection with as many cars as possible (from the 20 cars available). Furthermore, subjects were instructed that they should avoid crashes, and that they had two minutes within which to make all the crossings. (A clock was visible in the upper right section of the display [see Fig. 1]). The total session (with instructions and practice trials) lasted about five minutes per subject.

\section{Dependent variables}

The computer stored the following information for each subject's performance: number of opportunities (gaps physically large enough to cross, given the speed of the horizontal traffic and the acceleration of the subject's car-this measure is affected by the number of crashes, since each crash resulted in a "frozen" scene for five sec), number of successful crossings, number of crashes, and mean of the minimum clearance for all attempted crossings (see below for details).

The following three variables were selected for the analysis:

Probability of attempt. Attempts (successful crossings plus crashes) divided by opportunities. With the assumption that probability of attempt was inversely related to average gap size accepted, this variable was an indirect measure of attempted gap sizes. (A direct measure of gap size per attempt was not available.)

Probability of success. Successful crossings divided by attempts. This variable measured risk-level of performance.

Minimum clearance. Mean for all attempted crossings of the minimum separation between the subject's car and the four horizontally moving vehicles forming the gap in traffic; in pixels. This variable evaluated safety margins of performance. 
Only 14 of the 180 subjects (6 in the United States, 6 in Spain, and 2 in West Germany) made the maximum possible of 20 attempts within the two-minute limit. Furthermore, only two of these subjects (both from the United States) successfully crossed in all 20 attempts.

Analyses of variance were performed on all three dependent variables-probability of attempt, probability of success, and minimum clearance. The independent variables in these analyses were country, age group, and sex.

\section{Probability of attempt}

The mean probabilities of attempt by country, age, and sex are shown in Table 2 . The effect of country was significant, with U.S. subjects attempting to cross proportionally most often, followed by Spanish subjects, and West German subjects $(F(2,162)=7.70, p<.01)$. Effect of age was significant, with younger subjects attempting to cross proportionally most often, followed by middle-aged subjects, and older subjects $(F(2,162)=8.83, p<.01)$. Similarly, there was a statistically significant effect of sex, with males attempting to cross proportionally more often than females $(F(1,162)=7.34, p<.01)$.

Only one interaction-country by sex-reached statistical significance. Specifically, U.S. and West German males attempted to cross proportionally more often $(M=.75$, and .52 , respectively) than U.S. and West German females $(M=.53$, and .47 , respectively), while no difference was evident between Spanish males $(M=.57)$ and Spanish females $(M=.60)$

\section{Probability of success}

The mean probabilities of success by country, age, and sex are shown in Table 3. The only significant main effect was country, with West German subjects attaining the highest probability of success, followed by U.S. subjects, and Spanish subjects $(F(2,162)=3.23, p<.05)$. None of the interactions were statistically significant.

\section{Minimum clearance}

The mean minimum clearances by country, age, and sex are shown in Table 4 . The main effect of country was statistically significant, with U.S. subjects having the smallest minimum clearance, followed by Spanish subjects, and West German subjects $(F(2,162)=11.37, p<.01)$. The effect of age was marginally not significant $(F(2,162)=$ $2.73, p<.07$ ). (However, Scheffé's post-hoc comparisons indicate that younger subjects had smaller minimum clearance than a combined group of middle-aged and older subjects.) Finally, the effect of sex was statistically significant, with males having smaller minimum clearance than females $(F(1,162)=12.70, p<.01)$. None of the interactions were statistically significant.

Table 2. Mean probability of attempt by country, age and sex

\begin{tabular}{c|l|c}
\hline Independent variable & Level & $\begin{array}{c}\text { Mean Probabil1ty } \\
\text { of Attempt }\end{array}$ \\
\hline Country & $\begin{array}{l}\text { U.S.A. } \\
\text { Spain } \\
\text { West Germany }\end{array}$ & .64 \\
& $\begin{array}{c}\text { Younger } \\
\text { Middle-Aged } \\
\text { Age }\end{array}$ & .58 \\
\hline & Older & .66 \\
& Males & .55 \\
\hline Sex & Females & .51 \\
\hline
\end{tabular}


Table 3. Mean probability of success by country, age and sex

\begin{tabular}{c|l|c}
\hline Independent Variable & \multicolumn{1}{|c|}{ Level } & $\begin{array}{c}\text { Mean Probability } \\
\text { of Success }\end{array}$ \\
\hline Country & $\begin{array}{l}\text { U.S.A. } \\
\text { Spain } \\
\text { West Germany }\end{array}$ & .83 \\
& $\begin{array}{c}\text { Younger } \\
\text { Middle-Aged } \\
\text { Age }\end{array}$ & .87 \\
\hline \multirow{2}{*}{ Sex } & Older & .82 \\
& Males & .86 \\
& Females & .84 \\
\hline
\end{tabular}

\section{DISCUSSION}

\section{Effects of country}

The main aim of this study was to investigate whether there are any cultural differences in performance on a task simulating driver risk-taking behavior at an intersection. The results indicate that there were significant main effects of country on all three dependent variables. The primary differences were for West German subjects compared to U.S. and Spanish subjects. Specifically, West German subjects attempted fewer crossings, had a higher probability of success, and had greater safety margins. (Although there is no evidence in this direction, it cannot be excluded that the presumed effects of country are due to differential subject sampling.)

\section{Effects of age}

There was no age effect on the probability of success. However, younger subjects attempted proportionally most crossings, followed by middle-aged subjects, and older subjects. Finally, younger subjects had smaller minimum clearance than middle-aged and older subjects.

\section{Effects of sex}

There was no effect of sex on probability of success. However, males in the United States and in West Germany attempted to cross proportionally more often than did females, and males had smaller minimum clearance than did females.

\section{Probability of attempt vs. probability of success vs. minimum clearance}

The present data indicate that West German subjects tended to have a lower target risk-level of performance than did U.S. and Spanish subjects. This conclusion is based on the finding of a higher probability of success for West German subjects. To achieve this lower risk-level, West German subjects attempted crossings proportionally less often

Table 4. Mean minimum clearance by country, age and sex

\begin{tabular}{c|l|c}
\hline & Level & $\begin{array}{c}\text { Mean Minimum } \\
\text { Clearance (1n pixels) }\end{array}$ \\
\hline Independent Variable & U.S.A. & 9.9 \\
Spain & 10.0 \\
& West Germany & 12.9 \\
\hline Age & Younger & 10.0 \\
& Middie-Aged & 11.3 \\
& Older & 11.5 \\
\hline \multirow{2}{*}{ Sex } & Males & 9.9 \\
& Females & 11.9 \\
\hline
\end{tabular}


than did U.S. and Spanish subjects. The analysis of minimum clearance, measuring safety margins during attempts, suggests that the omitted opportunities involved smaller gaps. This conjecture is based on the fact that the minimum clearance for West German subjects was greater than for U.S. and Spanish subjects.

In comparison to the effect of country, there was no effect of age or sex on probability of success. This finding suggests that within each country all subjects (regardless of age and scx) tended to have the same target risk-level of performance. To achieve this common target risk-level of performance, both male and younger subjects attempted crossings proportionally more often than did female and older subjects. The analysis of minimum clearance, measuring safety margins during attempts, suggests that the additional attempts for both males and younger subjects involved smaller gaps, since the minimum clearances for male and younger subjects were shorter than for female and older subjects.

\section{Potential implications}

The results of this study suggest that West German drivers might have a lower risklevel of performance than do U.S. and Spanish drivers. (The target risk-level is considered by some researchers [e.g. Wilde 1988] to be the critical factor determining traffic safety in a given traffic system.) Consequently, it follows that if the present measure of probability of success was a valid indicator of actual in-traffic target risk-level, and if the West German traffic system was equivalent to that of the U.S. and Spanish systems, then German fatality rates would be lower than those in the United States and Spain. However, it is unclear whether subjects in the present study perceived the task as analogous to the real-world situation as intended. Furthermore, the traffic systems vary substantially among the three countries studied, whether in terms of the roadway network, vehicle population, and pedestrian/vehicle mix, for example. Consequently, statistics on fatality rates in the three respective countries cannot be used to assess the validity of the probability of success in the present task as an index of in-traffic target risk-level. (By the way, the statistics indicate that the 1985 fatality rate per 100 million vehicle kilometers in West Germany (2.3) was less than in Spain (5.4), but more than in the United States (1.5) [International Road Federation 1987].)

The present data also suggest that all subjects within each country studied, regardless of their age and sex, tended to have the same (country-specific) target risk-level of performance (as measured by the probability of successful crossings). However, if males and younger subjects were to attempt to cross gaps of the same difficulty (size) as females and older subjects, the presumed superior psychomotor skills and/or greater experience with video tasks of males and younger subjects would have led to higher probabilities of success for these subject groups than the target risk-level of performance. Consequently, males and younger subjects accepted smaller safety margins by attempting to cross smaller gaps (a conjecture), with resulting higher probability of attempts and smaller safety margins (both experimentally obtained).

\section{Concluding comments}

The experimental task was designed to simulate driver risk-taking behavior at an intersection. However, the degree to which this task was indeed perceived by subjects as analogous to the real-world situation is unknown. Consequently, determination of the applicability of the present results to driving must await a validation of the present task in relation to actual intersection-crossing behavior.

\footnotetext{
Acknowledgements - The authors express their gratitude to Hector Monterde i Bort, the designer of the test used in this study; to Manuel Juan Martinez, who did the computer programming; and to the Valencian firm General Asde S.A., which kindly assisted in the development of the test. Appreciation is also extended to John H. Chambers, A. Regula Herzog, and Paul L. Olson for their assistance and advice in conducting this research. This research was supported, in part, by the U.S.-Spain Joint Committee for Scientific and Technological Cooperation in Madrid, Spain.
} 


\section{REFERENCES}

Evans, L. Risk homeostasis theory and traffic accident data. Risk Anal. 6:81-94; 1986.

Fuller, R. G. C., A conceptualization of driving behaviour as threat avoidance. Ergonomics. 27:1139-1155; 1984.

International Road Federation. World road statistics 1982-1986. Washington, DC: International Road Federation; 1987.

McKenna, F. P. What role should the concept of risk play in theories of accident involvement? Ergonomics. 31:469-484; 1988.

Sivak, M.; Soler, J.; Tränkle, U. Cross-cultural differences in driver self-assessment. Accid. Anal. Prev. 21:371-375; 1989.

Sivak, M.; Soler, J.; Tränkle, U.; Spagnhol, J. M. Cross-cultural differences in driver risk-perception. Accid. Anal. Prev. 21:355-362; 1989.

Summala, H. Risk control is not risk adjustment: The zero risk theory of driver behavior and its implications. Ergonomics. 31:491-506; 1988.

van der Molen, H. H.; Bötticher, A. M. T. A hierarchical risk model for traffic participants. Ergonomics. 31:537-555; 1988.

Wilde, G. J. S. Risk homeostasis theory and traffic accidents: Propositions, deductions and discussion of dissension in recent reactions. Ergonomics. 31:491-506; 1988. 